\title{
Distinction of Road Categories by Road Users
}

\author{
G. Kosztolányi-Iván, Cs. Koren, A. Borsos \\ Széchenyi István University, Department of Transport Infrastructure \\ Egyetem tér 1, 9026 Győr, Hungary \\ e-mail: ivang@sze.hu
}

Abstract: In order to create self-explaining roads, a remarkable difference should exist between road categories, whereas within a given road category the layout should be homogenous. The paper analyses, how many and which road categories are identified and distinguished by road users. A picture sorting task was completed to find out how road users group 45 different road scenes, and how these groups correspond to road categories according current standards.

Keywords: road safety, road category, road scene, survey participants, driving speed

\section{Introduction}

A relatively new approach to safe road infrastructure is the self-explaining road. A selfexplaining road is a road designed and built in a way that it induces adequate behaviour and thereby less driving errors are expected. Therefore, road design parameters have to be used that promote the correct behaviour of road users.

The results of our previous surveys on Hungarian roads have shown that on the usual road categories like motorways and normal two-lane primary roads the speed choice is clear for road users, i.e. these roads are self-explaining. On the other hand, there are also road categories, which are not self-explaining and therefore road users have difficulties to choose the appropriate speeds [1]. To assess the degree of uncertainty of the drivers another survey was completed. This survey of requested speeds at various road scenes has shown that in unclear situations the standard deviation of chosen speeds is higher than in unambiguous situations and the inhomogeneous distribution of driving speeds can increase the risk of accidents [2].

In the road transport system the human factor holds the central role as far as the accident causation factors are concerned [3], [4]. Cross-sectional layout is very important from the driver's point of view regarding the proper behaviour during driving (for example choosing the appropriate driving speed). Therefore, cross-sectional layout of rural roads was investigated with different mathematical and statistical tools. The researches proved that the Hungarian rural road network design should be simplified; four types of crosssectional design would be necessary and sufficient in Hungary. With this simplification safe behaviour in traffic can be generated by the easier identification of behaviour forms required [5], [6]. 


\section{Classification of roads by road users}

\subsection{Picture sorting task}

Applying a method used by Weller et al. [7], a picture sorting task was performed with 104 university students. Respondents received road scene photographs in printed form with the description, which was similar to Weller's but with changes applied. The following description was used [8] [9]:

„You are about to see 45 pictures of roads; your task is to make a useful classification of these pictures $(3,4,5,6,7,8$, or 9 groups). Try to imagine yourself driving on the road and ask yourself how you would behave or which behaviour you would expect from other drivers on the same road. Sort pictures in such a way that the behaviour on the roads in a group is the same, and different from behaviour in other groups. There is no good or wrong sorting; make groups that you find useful yourself. Do this quickly, without thinking too long. You are free in choosing the number of pictures within each group and the total number of groups (between 3 and 9).

When your groups are ready, write each group (pictures marked with number on the back side) in separate columns on the other side of this paper. Write at least one - possibly more - key word for each group, which is typical for that group."

The aim of the survey was to explore how road users classify various road types and whether this distinction corresponds to road categories from our current design guidelines.

The 45 photographs depicted traditional road types, like motorways, expressway scenes and normal primary road scenes outside urban areas. A less well-known category is a main road with elevated speed limit of 100 or $110 \mathrm{kmph}$. Some of them had physical separation between traffic directions others did not. There were also urban roads and on the border of settlements often appearing transition zone also. Road types were sorted into nine categories according to the type of separation, number of traffic lanes and speed limit. Road types and their main characteristics are shown in Fig. 1.
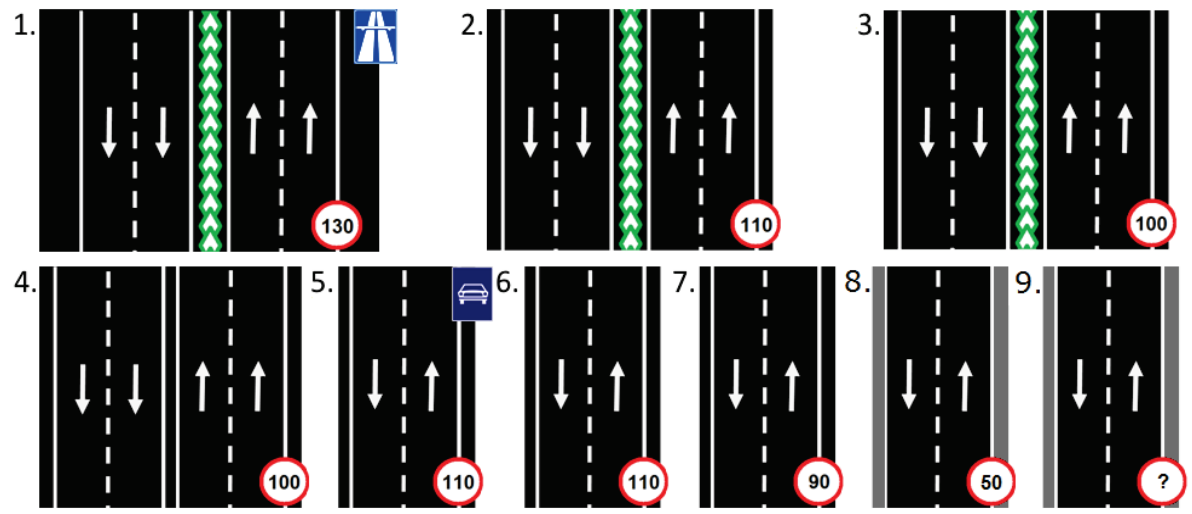

Figure 1. Schemes of the nine road categories and their posted speed limits 
Table 1. shows that respondents most often formed 4 or 5 groups from road scenes.

Table 1. Number of respondents depending on the number of groups created

\begin{tabular}{|c|c|c|}
\hline Number of groups & Respondents & Percentage \\
\hline 3 & 14 & $13 \%$ \\
\hline 4 & 27 & $\mathbf{2 6 \%}$ \\
\hline 5 & 28 & $\mathbf{2 7 \%}$ \\
\hline 6 & 20 & $19 \%$ \\
\hline 7 & 10 & $10 \%$ \\
\hline 8 & 4 & $4 \%$ \\
\hline 9 & 2 & $2 \%$ \\
\hline 5 & 104 & $100 \%$ \\
\hline
\end{tabular}

The most common key words used for the description regardless to the number of groups chosen, were urban area or inside built-up area, as well as the motorway or high speed.

To the group marked with the word motorway, respondents often added scenes of $2 \times 2$ lanes main roads with elevated speed limit in addition to normal motorway pictures. Reference to speed, low, medium or high speed, acceleration, reducing speed, braking or speed limit was often among the key words. Some respondents referred to safety or accident risk.

Respondents with four groups typically created two clearly separated groups: motorways and roads inside built-up area. The other two groups were variously formed; there were some who divided into good and poor pavement quality roads, while others described groups as expressway and main road. Some respondents referred to the number of traffic lanes or roadside trees as group features.

When choosing five groups, traffic volume was mentioned as key word, which was not typical for lower group numbers. Here visibility and presence of curves has also appeared as an influencing factor. Typical descriptions were: motorway - expressway - main road - minor road - built-up area, and motorway - high traffic volume - medium traffic volume - low traffic volume - built-up area. Some referred to the number of traffic lanes and distinguished transition zones from urban roads: motorway - 2x2 lane road - 2x1 lane road - road towards and leading out of city - built-up area. There were also who referred only to the driving speed: very high speed - high speed - medium speed - low speed - very low speed, and sometimes pedestrians and cyclist were also mentioned.

For persons sorting in six groups, categories according to the number of traffic lanes were typically further divided by presence or absence of physical separation between traffic directions.

Those respondents, who made seven or even more groups, often mentioned overpasses or presence or absence of emergency lane, in addition to the features mentioned above. 


\subsection{Cluster-analysis of road scene pictures}

The results of the picture sorting task were summarised in a symmetrical $45 \times 45$ matrix. The elements of this similarity matrix show, how many persons have put pictures $i$ and $j$ in the same group. The elements in the main diagonal of this matrix are equal to the number of respondents. From this matrix, a normalised one was generated, in which all the elements in the main diagonal are equal to 1 and all other elements are between 0 and 1 , showing the frequency of getting into the same group.

Figures 2-4 show details from the summarized matrix with pairs of pictures. Fig. 2 shows that $86 \%$ of the respondents put pictures 4 and 7 into the same group. Both pictures show primary rural road scenes, this grouping fits well to the real classification.

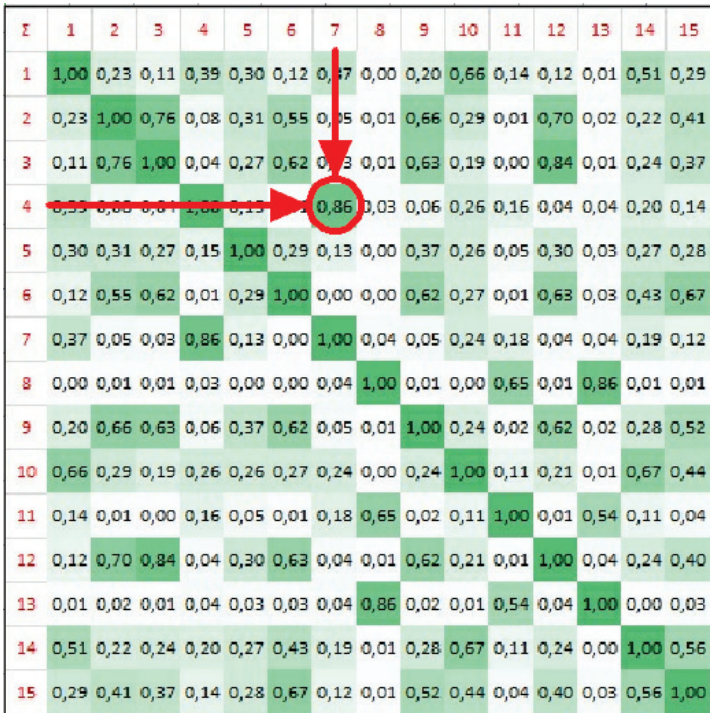

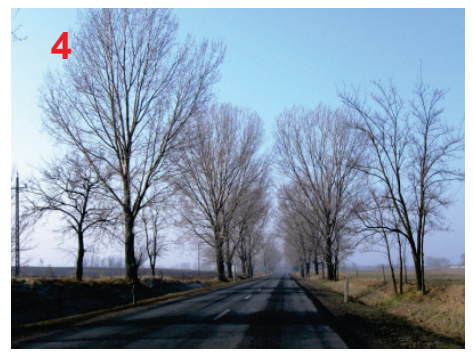

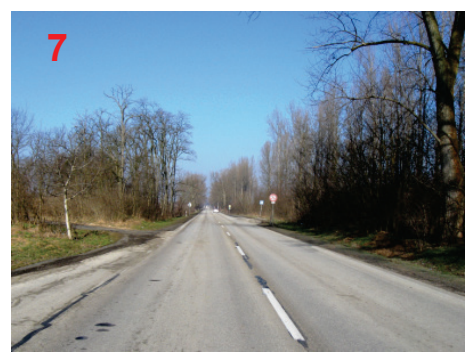

Figure 2. Detail A from the similarity matrix

In Figure 3, pictures 6 and 12 belong to different road categories: picture 6 shows a dual carriageway road with elevated speed limit of $100 \mathrm{kmph}$, while picture 12 is a motorway. Despite this difference, $63 \%$ of respondents felt that they belong together. The similarity between these categories can mislead road users. 

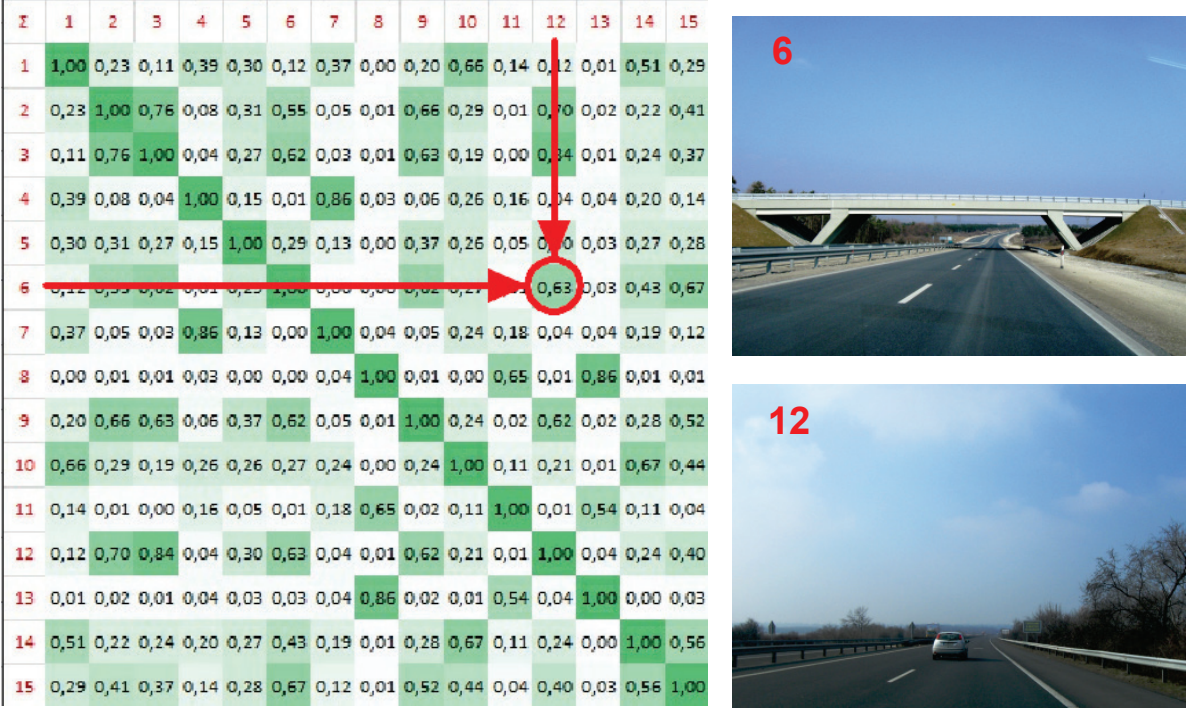

Figure 3. Detail B from the similarity matrix

Fig. 4 shows a pair of pictures, where the cross-sections are quite different with $2 \times 2$ lanes in picture 9 and $2 \times 1$ lanes in picture 14. Despite this crucial difference, 28 percent of respondents linked these two pictures, thinking that they belong to the same category.
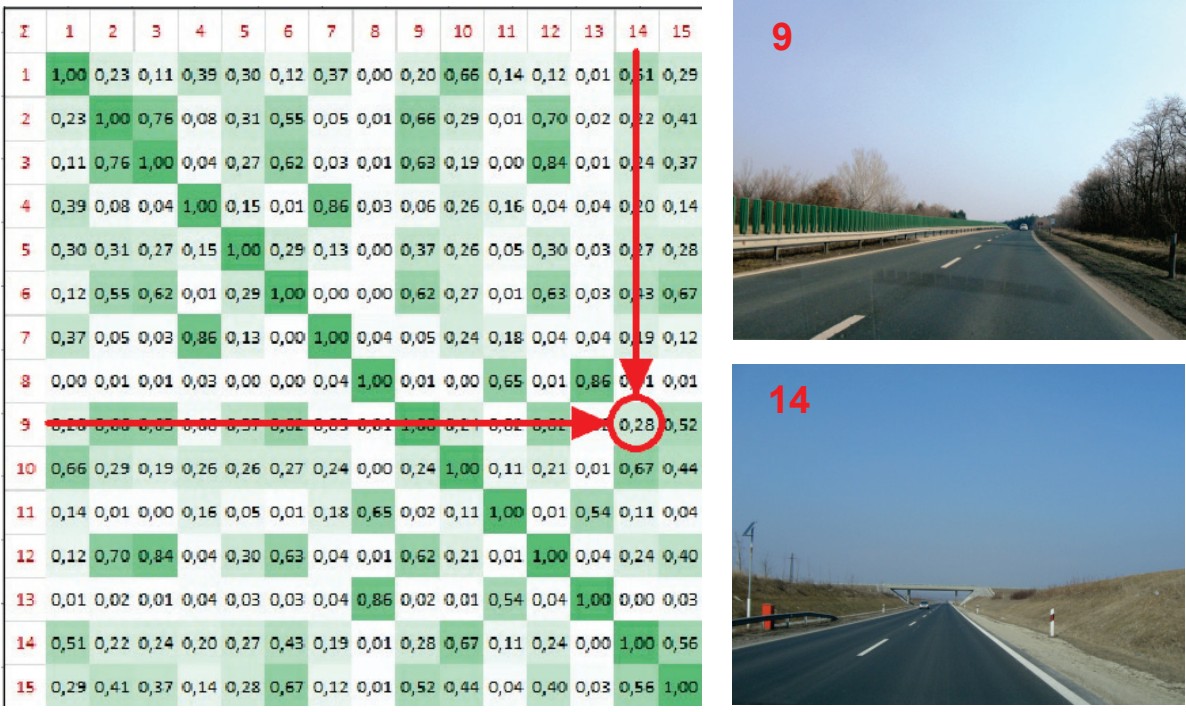

Figure 4. Detail C from the similarity matrix

For the further data analysis, the cluster analysis module of SPSS software was used. The method of hierarchical clustering seemed to be most appropriate.

The agglomerative algorithm is a 'bottom up' approach, each observation (here each picture) starts in its own cluster, and pairs of clusters are merged as one moves up the 
hierarchy. At the end we get one cluster, which contains all elements. The results of hierarchical clustering are usually presented in a dendrogram, showing the merging process. If the tree is cut at a certain height, at that point the results of clustering can be interpreted.

There are various agglomerative clustering methods, this program applies the 'average linkage clustering' method, where the distance of two clusters is determined based on pair-wise average distance of all the elements, where one element of the pair belongs to one cluster and the other element to another cluster.

The more participants placed the given pair of pictures into the same group, the earlier these road scenes were linked in the dendrogram (Fig. 5). Therefore, the further away two pictures are from each other, the fewer participants put them into the same group.

The dendrogram showed in Fig. 5 was cut at five branches. On the horizontal axis each picture is marked with a number, on the vertical axis the rescaled distances of clusters are shown. Vertical lines show joined clusters. The position of the line on the scale indicates the distance at which clusters are joined. The observed distances are rescaled to fall into the range of 1 to 25 therefore the actual distances are not shown. However, the ratio of the rescaled distances within the dendrogram is the same as the ratio of the original distances.

From left to right, the first group contains $2 \times 1$ lane roads with elevated speed limit and $2 \times 1$ lane expressways. Roads with $2 \times 2$ lanes and elevated speed limit, without physical separation are in the second group. All 2x1 lane main rural roads belong to the third group. The fourth cluster contains roads with physical separation between traffic lanes: motorways and $2 \times 2$ lane roads with elevated speed limit. All urban roads and roads of transition zones are collected in the fifth group. This is a clear classification system.

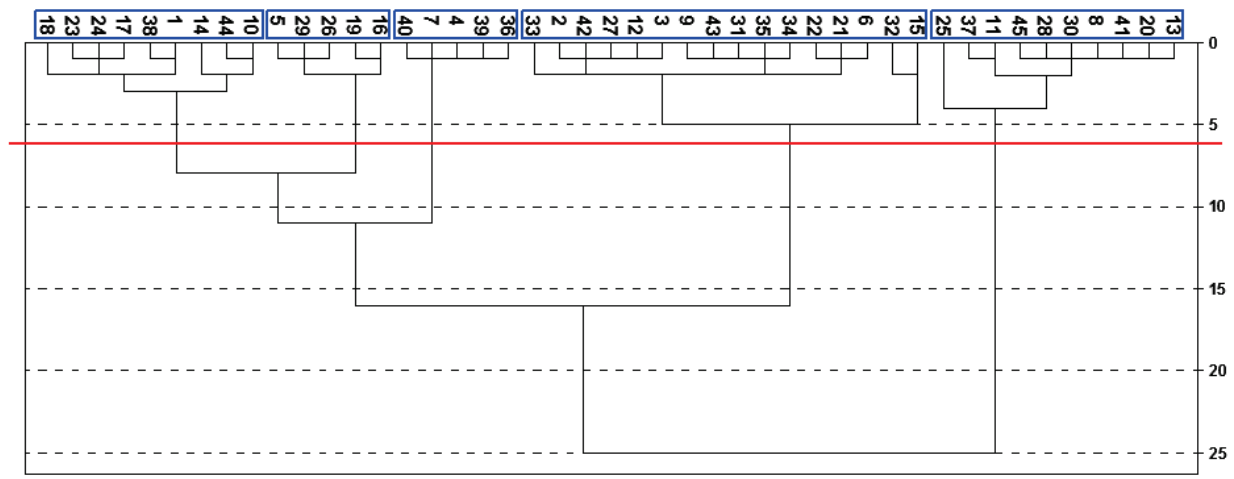

Figure 5. Dendrogram for all groups

If one stops the process at more clusters (moving the red line upwards one or two steps), no such clear classification can be found. Consequently, the picture sorting exercise shows that only 4-5 road types can be clearly distinguished by road users.

Next, some detailed results will be shown using the dendrogram, highlighting some parts of it. 


\subsection{Detailed results of the cluster-analysis}

From the picture series 8-41-20-13, shown in Fig. 6, it is clear that all of these were taken on urban road sections. The classification made by the respondents is corresponding to the reality, as these images were classified into the same group by the majority of respondents and linked together in the first phase of clustering.

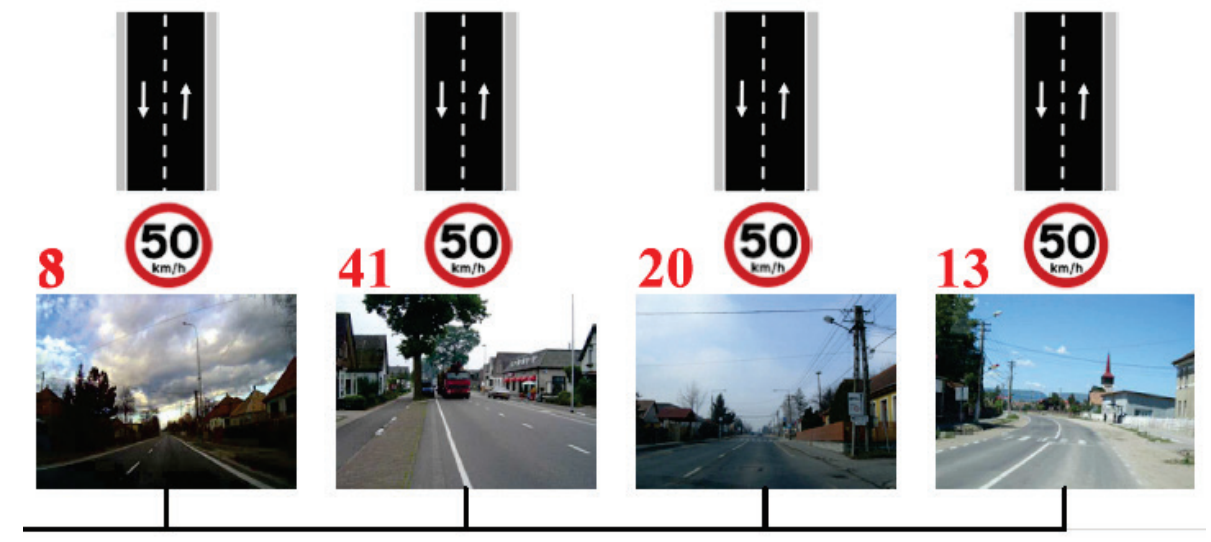

Figure 6. A detail from the dendrogram-urban road scenes correctly linked at first step

The same results can be observed for main roads outside built-up areas and for motorways. Pictures 40-7-4 (Fig. 7) were connected at the first step, as well as pictures 27-12-3 that were taken on motorways (Fig. 8).
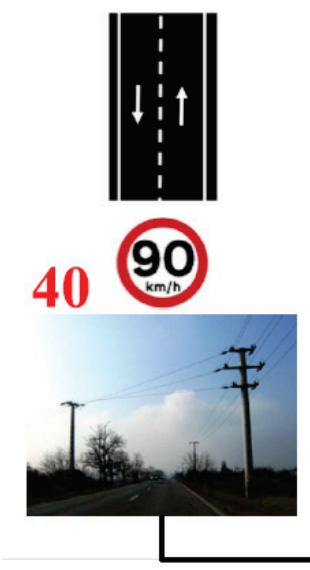
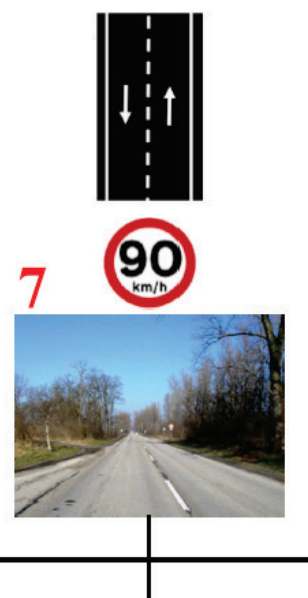
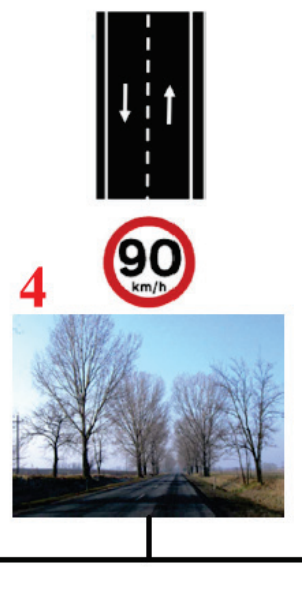

Figure 7. A detail from the dendrogram - rural main road scenes correctly linked at first step 

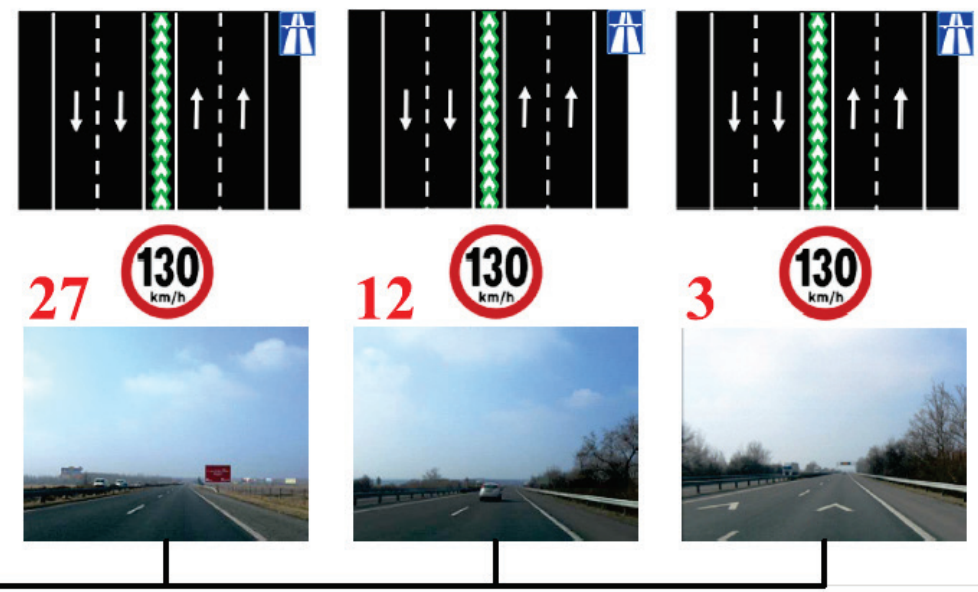

Figure 8. A detail from the dendrogram - motorway scenes correctly linked at first step

Picture group 2-42-27 (Fig. 9) was also linked at first step, that means according to the respondents they clearly belong together. Apparently this is a false classification, since the pictures 2 and 27 were actually taken on a motorway, while image 42 represents a $2 \times 2$ lane dual carriageway road with elevated speed limit of $100 \mathrm{kmph}$. So there should be noticeably $30 \mathrm{kmph}$ speed difference between these two road types.

According to the similarity matrix, the ratio of placing pictures 2-27 into one group is 0.70 , for pictures $2-42$ it is 0.66 and for scenes $27-42$ is 0.79 . For these reasons, we conclude that $2 / 3-3 / 4$ of respondents cannot distinguish $2 \times 2$ lane dual carriageway roads with elevated speed limit from motorways.
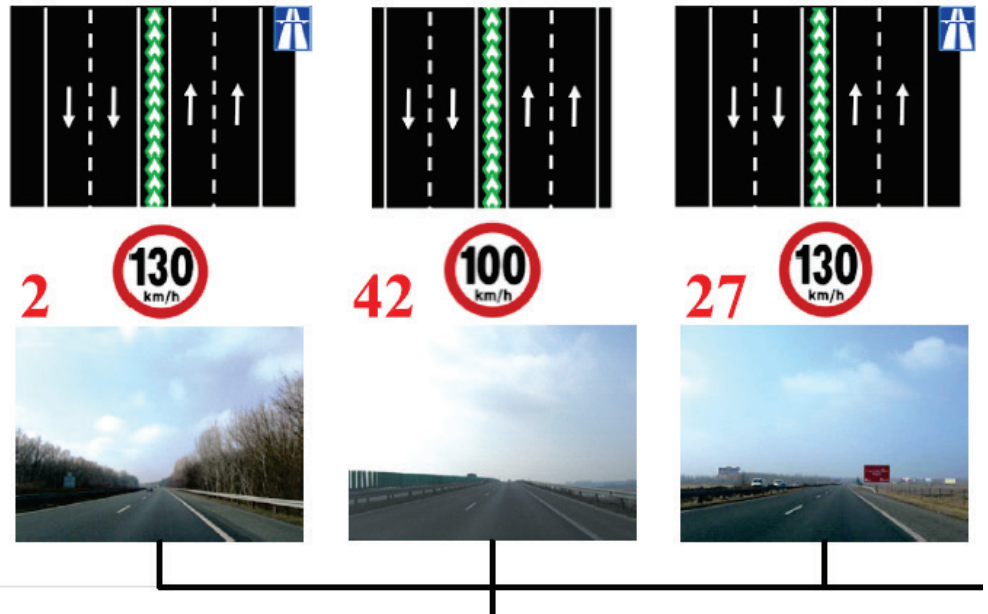

Figure 9. A detail from the dendrogram-incorrectly linked scenes at first step 
The early linking of pictures 22-21-6 (Fig. 10) shows that the grouping is influenced by individual road elements. These three pictures show three different road types, but each contains a bridge over the road. These pictures were linked at the first step and merged with the group of other dual carriageway roads at the second step only. According to the similarity matrix, the ratio of placing pictures $22-21$ into one group is 0.74 , for pictures $22-6$ is 0.76 and for scenes $21-6$ is 0.81 .
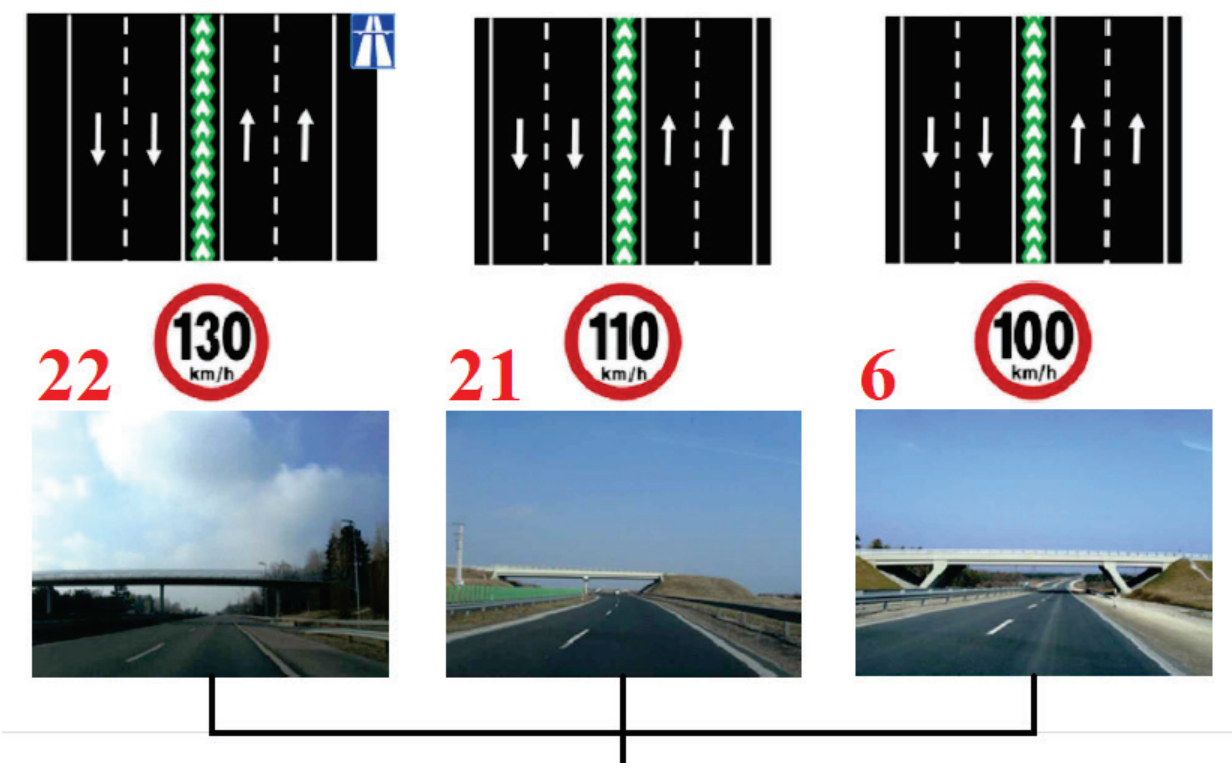

Figure 10. A detail from the dendrogram-scenes linked at first step incorrectly, due to similar road elements

The respondents get into difficult situation when grouping the scenes of transition zones; they were not able to connect these pictures with each other, as it is visible in Fig. 11. Picture 45 was placed into the group of urban roads at first step. Pictures 37 and 11 were linked with each other in the first step and then, in the second step they were merged to the urban roads group. Picture 25 was added to this mix of urban and transition road's group only at fourth step (Fig. 12.). 

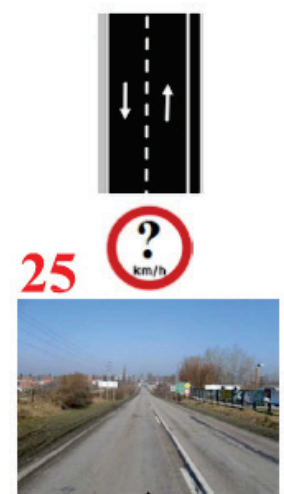

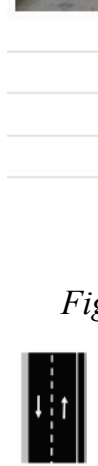

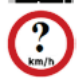

25
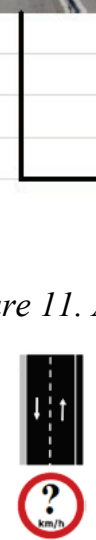
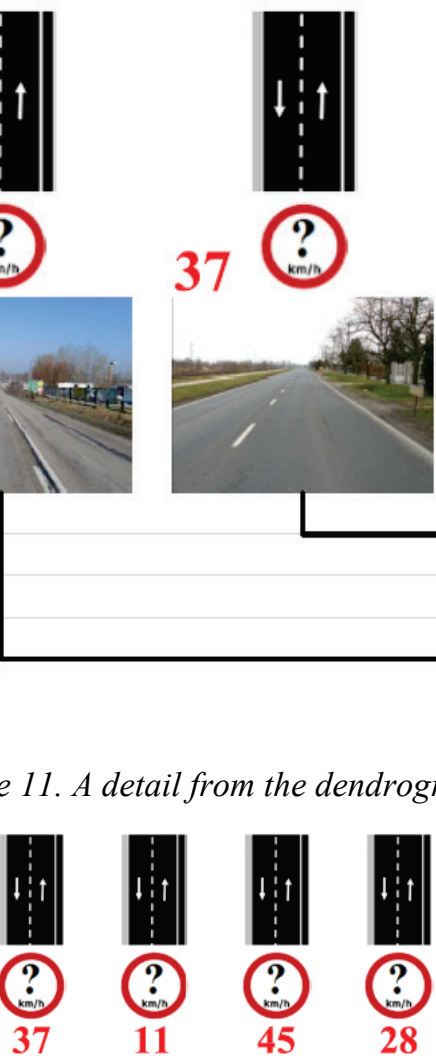
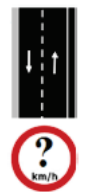

11
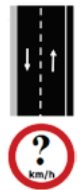

45
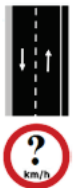

28
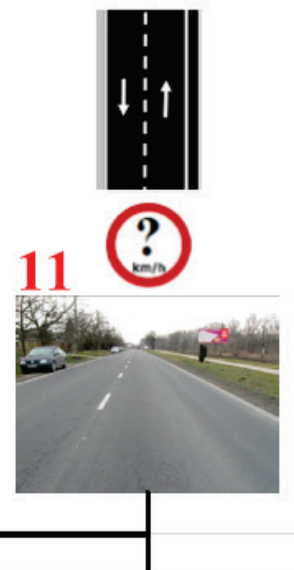

$\mathbf{T}$

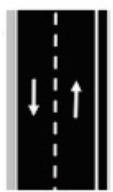

?
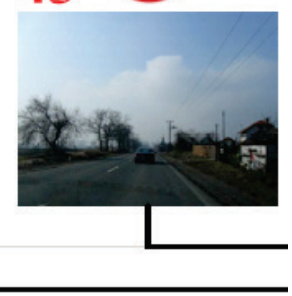

Figure 12. A detail from the dendrogram-scenes linked at later steps

\section{Classification of roads according to speed choice}

The choice of speed by drivers mostly depends on the layout and conditions of the environment of the road and the current traffic conditions on it [10], [11], [12]. Different geometric parameters of roads have different effects on vehicle speeds [13], [14], [15], [16], [17]. There are a number of researches dealing with how driving speeds affect the safety of road infrastructure [18], [19], [20], [21].

The speed choice of road users has traditionally been measured by speed cameras on the roads. Some studies apply another method: respondents had to choose driving speed according to road scene photographs, which were shown them [22], [23], [24]. Similarly to the studies mentioned above, driving speeds were studied by a questionnaire survey [25], [26].

In our questionnaire survey respondents had to review photographs of road scenes. Participants were asked to state what speed they preferred for each road scene, they were 
not informed about the actual speed limit. The aim of the study was to explore how road users can recognize various types of roads.

According to the average of chosen driving speeds and the standard deviation clearly and unclearly identified roads were reported earlier [27], [28]. After that a further analysis was made [9]. Similarly to the picture-sorting task presented above, according to the speed choice exercise, road users can only distinguish 4-5 road types clearly. Additional clusters cannot be clearly linked to road types.

\section{Conclusions}

The results confirmed previous investigations that some road types are recognizable for road users while there are also roads that cause uncertainty; these roads are not selfexplaining. As uncertainty can cause risky situations, in these sections road users should be informed with special care about their expected behaviour.

Traditional road classification distinguishes a high number of road categories. The Hungarian road design guidelines outside built-up areas define 8 different design categories and within each category there are also additional 2-3 'subcategories' distinguished [29]. Therefore about 15 different types of rural roads can be designed.

According to the cluster analysis based on chosen driving speeds, as well as in the picture sorting task, the result is that road users can clearly distinguish only 4-5 road categories. These numbers are in harmony with the new German and Dutch classifications, which are also based on this observation [30], [31], [32]. It is proposed to upgrade the Hungarian technical specifications, guidelines according to these principles.

\section{References}

[1] Iván G, Koren Cs: Survey of free speeds on roads outside built-up areas with elevated speed limits in Hungary. Journal of Society for Transportation and Traffic Studies, Vol. 4, No. 2, pp. 8-17, 2013.

[2] Iván G, Koren Cs: Recognition of built-up and non-built-up areas from road scenes, Transport Research Arena 2014. Innovate Mobility, Paris, France, 2014.04.14-17., Paper 18069, p. 9, 2014.

[3] Berta T: The human as a part of the transport system (in Hungarian). Közúti és Mélyépítési Szemle, Vol. 57, No. 12, pp. 20-24, 2007.

[4] Holló P: Thoughts on the role of human factors in road safety (in Hungarian). Közúti és Mélyépítési Szemle, Vol. 57, No. 12, pp. 25-26, 2007.

[5] Török Á: Simplification of road transport infrastructure layout for better selfexplanation. American Journal of Vehicle Design, Vol. 1, No. 1, pp. 16-20, 2013.

[6] Hlédik E, Lógó E, Török Á: The assessment of cross-sectional arrangement of road traffic infrastructure with mathematical methods (in Hungarian).

Közlekedéstudományi Szemle, Vol. 62, No. 6, pp. 15-20, 2012.

[7] Weller G, Schlag B, Friedel T, Rammin C: Behaviourally relevant road categorisation: A step towards self-explaining rural roads. Accident Analysis and Prevention, Vol. 40, pp. 1581-1588, 2008.

DOI: $10.1016 /$ j.aap.2008.04.009 
[8] Iván G, Koren Cs: Distinction of road classes in design guidelines and from the viewpoint of road users (in Hungarian). XVII. International Conference on Civil Engineering and Architecture, Hungarian Technical Scientific Society of Transylvania, Csíksomlyó, Romania, pp. 130-137, 13-16 June 2013.

[9] Iván G: Distinction of road categories by road users compared to road classification in design guidelines. Pollack Periodica, Vol. 9, No. 3, pp. 23-34, 2014.

DOI: $10.1556 /$ Pollack.9.2014.3.3

[10] Berta T, Török Á: Layout effect of roadway on road vehicle speeds. Pollack Periodica, Vol. 4, No. 1, pp. 115-120, 2009. DOI: $10.1556 /$ Pollack.4.2009.1.12

[11] Edquist J, Rudin-Brown Ch. M, Lenné M: Road design factors and their interactions with speed and speed limits. Monash University Accident Research Centre, Report No. 298, 2009.

[12] Bella F: Driver perception of roadside configurations on two-lane rural roads: Effects on speed and lateral placement. Accident Analysis and Prevention, Vol. 50, pp. 251-262, 2013. DOI: $10.1016 /$ j.aap.2012.04.015

[13] Ivan JN, Thomas J, Borsos A: Motor vehicle speeds: Recommendations for urban sustainability. Transportation Research Record, Vol. 2301, pp. 1-8, 2012. DOI: $\underline{10.3141 / 2301-01}$

[14] Vörös A: Examining the driver's practice of choosing speed on some peripheral higher-speed road sections with mixed traffic (in Hungarian).

Közlekedéstudományi Szemle, Vol. 59, No. 1., pp. 37-48, 2009.

[15] Ivan JN, Garrick NW, Hanson G: Designing roads that guide drivers to choose safer speeds, Connecticut Transportation Institute of the University of Connecticut. Technical Rport, No. JHR 09-321, 2009.

[16] Brewer J, German J, Krammes R, Movassaghi K, Okamoto J, Otto S, Ruff W, Sillan S, Stamatiadis N, Walters R: Geometric design practices for European roads, American Trade Initiatives, Technical Report, No. FHWA-PL-01-026, 2001.

[17] Findley DJ, Hummer JE, Rasdorf W, Zegeerd Ch. V, Fowler TJ: Modeling the impact of spatial relationships on horizontal curve safety. Accident Analysis and Prevention, Vol. 45, pp. 296-304, 2012.

DOI: $10.1016 /$ j.aap.2011.07.018

[18] Mocsári T: Speed is the source of all trouble (in Hungarian). Közúti és Mélyépítési Szemle, Vol. 54, No. 9, pp. 14-18, 2004.

[19] Mocsári T: Effect of vehicle speed on the safety of road infrastructure (in Hungarian). PhD Thesis, Multidisciplinary Doctoral School of Engineering Sciences, Széchenyi István University 2012.

[20] Borsos A: Optimizing and modeling the safety effects of road infrastructure measures (in Hungarian). PhD Thesis, Multidisciplinary Doctoral School of Engineering Sciences, Széchenyi István University, 2010.

[21] Gaca S: Speeds, sight distances, sight fields in road design - their impact on traffic safety (in Hungarian). Közúti és Mélyépítési Szemle, Vol. 54, No. 9, pp. 9-13, 2004. 
[22] Garrick NW: Speeds and street design results UConn and UCD. Highway design class, University Lecture, University of Connecticut, 2011.

[23] Goldenbeld Ch., van Schagen I: The credibility of speed limits on $80 \mathrm{~km} / \mathrm{h}$ rural roads: The effects of road and person(ality) characteristics. Accident Analysis and Prevention, Vol. 39, pp. 1121-1130, 2007.

DOI: 10.1016/j.aap.2007.02.012

[24] Lahausse JA, van Nes N, Fildes BN, Keall MD: Attitudes towards current and lowered speed limits in Australia. Accident Analysis and Prevention, Vol. 42, pp. 2108-2116, 2010.

DOI: $10.1016 /$ j.aap.2010.06.024

[25] Iván G: Safe speed choice from the viewpoint of road users. 8th European conference of young researchers and scientists - Transcom 2011, University of Žilina, Slovakia, 27-29 June 2011, pp. 67-70.

[26] Iván G: Survey of free speeds on rural roads based on road scene photographs. Pollack Periodica, Vol. 7, No. 1, pp. 65-74, 2012.

DOI: $10.1556 /$ Pollack.7.2012.1.6

[27] Koren Cs, Iván G: Survey of speed choices based on photos (in Hungarian), XV. International Conference on Civil Engineering and Architecture. Hungarian Technical Scientific Society of Transylvania, Csíksomlyó, Romania, 2-5 June 2011, pp. 303-309.

[28] Iván G, Koren Cs: Are roads with elevated speed limits self-explaining? (in Hungarian). Közlekedésépítési Szemle, Vol. 61. No. 5, pp. 30-36, 2011.

[29] HRS, Road Planning Guideline (in Hungarian) No. e-UT 03.01.11, Hungarian Road Society, Ministry of Transport, Telecommunication and Energy, 2008.

[30] Koren Cs: Classification of roads, Safety of road infrastructure (in Hungarian). Ed. by Koren Cs, Győr, Universitas-Györ Non-profit Kft, pp. 87-96, 2012.

[31] SWOV, Fact sheet sustainable safety: principles, misconceptions, and relations with other visions. SWOV, Leidschendam, the Netherlands, 2010. http://www.swov.nl/rapport/Factsheets/UK/FS_Sustainable_Safety principles.pdf, (last visited 20 December 2013)

[32] FGSV, Richtlinien für die Anlage von Landstraßen RAL. Forschungsgesellschaft für Strassen- und Verkehrswesen, Köln, 2013. 